\title{
Representation of the morphological information at the level of lexical input during the process of speech decoding: philological and phenomenological hermeneutics vs. psycholinguistic models
}

\author{
Rashid Alikaev - Marianna Asanova - Tatiana Shiryaeva - Tatiana \\ Cheprakova - Sergey Bredikhin
}

DOI: 10.18355/XL.2018.11.01.07

\begin{abstract}
The article suggests a model of constructing a non-contradictory algorithm for detecting morphological formants in the process of decoding natural language. The priming effect in the current study correlates with the prognostic strategies within the hermeneutical and noematic method. The article offers the results of experiments on lexical priming input of the morphological information and the representation of meaning overtones in German and Dutch phrasal verbs. The authors conclude that constitutional priming implementation is characterized by a repeated realization of phonetic/orthographic components. Each priming effect includes processes that reflect affinity activation between a generalized meaning of the compound word and the associations.
\end{abstract}

Key words: psycholinguistics, mental lexicon, priming effect, prognostic strategies, speech decoding, semantic affinity, meaning overtone

\section{Introduction}

The issue of representation of words and their morphological structure within the system of a language has been subject to close study for several years now, both in theoretical linguistics of A. Spencer (1991), and in computer linguistics and applied information science (Farke, Felix, 1990; Hankamer, 1991). The problem under study has also been touched upon in psycholinguistics (Günther, 1989; Henderson, 1991), where the previously offered data is seen as a valuable piece of information, which may have an impact on the way the following data is perceived and interpreted. Although all of the abovementioned disciplines have pursued different aims, they have a common ground for research. Starting with a linguistics standpoint, which focuses on the question of correlation between the content of lexicographical material or media carriers, and the lexical system of a language, a problem arises that concerns the inclusion or exclusion of all word forms, including morphologically complex words of different types, into a general cognitive lexicon or into a separate sphere of rule-based derivation of such constructions (Grudtsina, Galushkin, 2013; Galushkin, 2015). Kong, Kayumova, Zakirova, 2017). Rather often specific transformation models that allow generating non-usual poly-dimensional meanings through changing the concept in the noematic super-structure prove to be not absolutely new yet are reconceptualized derivational models, which are the ones that do allow objectivizing the total generalized sense displaying certain features and "individual" conceptual traits.

In this article, we intend to look at different psycholinguistic models in regards to the correlation between the morphological structure of word forms within the formal indicators (orthographic/phonological) and markers of the inner form (including the distribution of the meaning components) and their lexical way of representation. In fact, this article is not limited to the theory of formal word differentiation, but instead, we introduce the newest studies in the field of philological and phenomenological hermeneutics whose concepts have been more than once on our focus. Considering the ways for building models of perceiving and recognizing the in-depth structure of 
an utterance based on "the scheme of acting" for generating and decoding sense, is the very correct act of intending, which allow solving the issue of consistent implementation of priming in target utterances. The actual possibility of constructing meaning overtones "based on either existing models (of constantly recurrent and fixed structural set of noemas) or based on occasional construction (not typical of the usage of the conglomerate and a new hierarchical structure, non-related noemas within a model), as well as the possibility of forming a semantic construct based on subjective modality, are the very processes that push the speech producer beyond the limits of the aforementioned reflexive reality towards the need of a conscious or intuitive reflection" (Bredikhin, 2013a). The complex integral model based on the lexical expectation, which, actually, includes the major prognostic strategies in the priming functioning, offers a possibility for clarifying basically all the actual cases of structurally and semantically ambiguous units in the utterance as well as reduces the amphibology issue in a parallel use of the "core element projection" hypothesis and the functional category analysis.

\section{Research Methodology}

The article discusses the utterance perception and interpretation studies, where the phonetic/orthographic and semantic similarity influences and explicitly varies in complicated morphological structure processing. In the light of philological phenomenological hermeneutics methodology, the given research demonstrates the following: root-priming effect and phonetic/ orthographic priming create a similar effect in producing/decoding of generalized meaning in the nomination process. In the course of lexical-semantic representation decision-making, there is a wide range of disassociative effect priming techniques in the form of prognostic and inhibitory effect that cannot be explained by standard psycholinguistic models, which treat coding and morphological structure input as the discharge of phonetic/orthographic representations on the formal level of the hypothetical mental lexicon. The analysis of morphological structure representation becomes possible through the research study of the deep semantic content shape and features based on the hermeneutic-noematic method; this statement is confirmed by the empirical data on the lexical entry representation level of any mono- or polimorpheme word-form, where the attribution to any basic morpheme is encoded through the relationship between the input levels.

It should be noted that the degree of activation depends on the amount of perceived similar semantic characteristics of Target and Prime. Associative priming experiments with German and Dutch phrasal verbs demonstrate a method in which non-transparent phrasal verbs not only activate the pre-association, which comply with their specific meanings but pre-activate the phrasal verb meaning, containing the basic morpheme with generalized meaning.

These issues are especially relevant in the research of conditional phrasal verbs divisibility based on transparency criteria (basic verbs and the particles are divided into declarative and imperative sentences). During the statement processing where the recipient is able to use a basic verb as a Prime, phrasal verb transparency and nontransparency require more time and effort in producing a phenomenological reflection. Phrasal verbs can be analyzed not only in terms of semantic representations and morphological structure coding but also from the standpoint of lexical and syntactical components conjugation within the utterance production.

The linguistic analysis confirms the variation of semantic similarity between morphologically complex and basic lexemes. The data indicate that connecting structures represent the correlation of morphologically related word-forms and semantic variations, in other words, due to formal peculiarities morphologically complex word-form representation is activated and all further representations of rootpriming are untenable.

XLinguae, Volume 11 Issue 1, January 2018, ISSN 1337-8384, eISSN 2453-711X 


\section{Results and Discussion \\ The critique of psycholinguistic approaches}

By the beginning of the 1970-s identification of the lexical composition and its structuring have come to occupy the most important place in studies devoted to speech decoding. Gradually some new and essentially different models of speech identification and realization of morphological meanings have emerged (Carr, Pollatsek, 1985), which, however, are based on one and the same proposition. According to the latter, the process of words decoding includes many different lexical components, within which specific lexical and morphological information is encoded and processed. Generally, there is a difference between the lexical access (Forster, 1981), or the input level of the content components (term as suggested by M.S. Seidenberg and J.L. McClelland (1989), and the lexical level of output. In philological and phenomenological hermeneutics the level of input has a disobjectivizing aspect to it, while the level of output is for us an objectivation level. Formal lexical features play the defining role at the lexical level of access, or the input level, i.e., orthographical and phonological information is encoded into the words. Access to the form of representation or the analysis of formal characteristics of the external stimulus is a necessary condition for the selection of lexical components, which introduce information associated with the inner content of the word (a generalized multifaceted product). Among other things, these components include the general meaning of the word or the structural information about the possibilities of its usage in various syntactical contexts (e.g., the category of the word, the structure of the argument). At the level of output, the most important role in the process of speech decoding belongs to phonological and articulatory features, which define and mark pronunciationrelated characteristics of a word. Currently, based on the model of general lexical structures, a lot of assumptions have been made in regards to processing and representation of morphologically complex words.

All of the existing psycholinguistic models which stem from the proposition that morphological structure has one of the most important roles in the process of decoding isolated words (words without a context), as a rule, differ on one account deciding at which level of mental lexicon the processing and encoding of morphological information takes place.

Some of the theories rely on the postulate which suggests that the encoding of the morphological (surface) structure happens at the level of lexicon input. An important feature of these models is that the processing of formal characteristics of the visually represented sequence of graphical elements or the sequence of sounds represented linearly in time includes morphological decompositional mechanisms as well, which isolate the route morpheme (free route). Orthographic representation, which is taken into consideration for further analysis, is encoded either in the form of a route morpheme (Taft, Forster, 1975) or, in the form of a full word along with the morphologically-segmented encoding (Route + Affix) (Frauenfelder, Schreuder, 1992).

It is important to look into another theory which has been developing in the opposite direction, and according to which any representation of the morphological structures as components of a word's inner content is predefined before the lexicon input level. These models presuppose that each form of the word is considered to be an independent speech unit. The appearance of morphological variants with the same basic morpheme (invariant) is viewed as a paradigmatic hierarchy (Feldman, 1991). Thus, attribution to the route within the paradigm of the forms generation realizes the lexical principle of organization.

Basically, each of the described theories may be confirmed with the help of extensive empirical material, but the initial theoretical premises differ. Moreover, the degree to 
which an uttering of a potential recipient can be verified within his conceptual system does not always match.

An important component of the morphological decomposition theories is a supposition that the frequency of a word-form influence is directly connected with the degree to which the priming effect is realized, i.e., word-forms with a frequent usage may be identified faster than those that have a less frequent usage. This primarily has to do with a high representation and a high level of the incoming signal in the lexical paradigm. Consequently, the postulate about the effect of the route encoding morpheme at the orthographic/phonetic level of access is based mainly on the studies that show that the usage frequency of the graphic symbols/acoustic units, which correspond to the route morpheme, has a special status in the process of a false decoding of pseudo-words and morphologically complex words. Nevertheless, even those who share this point of view cannot reach a mutual opinion (Taft, 1991; Bergman, Hudson, Eling, 1988).

The route-priming effect can be traced in a much more stable and consequent way when fulfilling lexical tasks in inflective and agglutinative languages. The experimental procedure of detecting route-priming effect has the following structure: two sequences of graphical or phonetical symbols (preliminary and targeted) are represented consequently in the process of measuring the reaction time which a person needs to realize that a sequence belongs to the system of the native language. An example of this procedure can be illustrated via an association-based experiment of the liminal perception of a word-form with an affix "-ed" in the English language (e.g., called) and measuring the speed at which one realizes that the word-changing morpheme belongs to the category of tense, and then subsequently detects the base form (call), which, compared to the input-form, is a reduced form (e.g., in English showed - show). Nevertheless, there is a number of examples contrary to this assumption (Henderson, 1991). From this point of view, the discussion of the linguistic theory of lexical morphology should be abandoned, and the generating morphology of the speech act should be adopted instead.

A very interesting question in this regard is that of the semantic and morphological representation of compound words in the mental lexicon. They have common features of the surface structure, common derivational and compositional characteristics but at the same time, they verbalize different meaning overtones because of the representation of different morphological information in the components. The morphological and derivational processes that happen along with the major changes of the meaning hierarchy have been ignored in psycholinguistic models that study the representation of morphological information (Miller \& Johnson-Laird, 1976). Only a few works are devoted to studying the semantic and morphological processing and representation of compound word-forms - the fact that suggests some certain basis for building a model concerned with disobjectivization of the meaning hierarchy.

As an example of the theories based on the study of morphological components, let us take a look, firstly, at the route-priming effect as a case of the priming condition - a condition of a liminal prospective perception and decoding (Grainger, Cole \& Segui, 1991). It is assumed, that the most nucleus component of the lexical meaning is outlined in the process of speech production with the help of marking and that the process of lexical meaning recognition can be timed.

The route-priming effect does not only show itself in short- or long-term primingconditions (liminal perception), but it is also realized through the consequent or simultaneous perception of several core lexical meanings, i.e., in the conditions of interweaving stimuli (Schriefers, Friederici, Graetz, 1997). Alternatively, it is realized through the splitting of the lexical meaning perception at the time intervals ranging from a minute to an hour (Murrell \& Morton, 1984).

XLinguae, Volume 11 Issue 1, January 2018, ISSN 1337-8384, eISSN 2453-711X 
Each long-term route-priming effect may be studied at the early stage of disintegration of the activation process, which lies in the formal analysis of external stimuli. The results of long-term priming paradigms are also connected with the main notions of the theory which defines the representation of the morphological structures of content components in the lexicon. The notions such as the one which says that complete word-forms are immanently encoded into the lexical representations that connect all correlating morphemes should also be taken into consideration. This postulate has been confirmed more than once in different studies according to which regular flectional word-forms originate within the strong priming effect, while irregular flectional or derivational word-forms are realized in the weak priming effect accordingly (Stanners at al., 1979).

Interpretation of the redecoding process within the route-priming effect is aimed at detecting morphologically-related word-forms, which is an easy way to establish affinity at the orthographical/phonetical and semantical levels. However, it should be noted that the analysis of a real hermeneutical understanding is not conducted in the process of real speech production as the semantic construction of the form does not always conform to a noematic meaning hierarchy. That is why it is necessary to include the constants of meaning generation and a number of steps of the hermeneutical and noematic method into the corresponding theory, which, however, can lead to both the decrease or increase of the implicit reaction time to the prime/target pair. This pair consists of the same route morphemes - the fact that can be explained from the point of view of the similar orthographic and phonetic characteristics activation or similar views of the immanently predefined meanings within the effect of the dominant noemas and culture-defining noemas. The described characteristic is common in morphologically-related word-forms, and, naturally, it reflects the closeness of external factors and meaning overtones within similar orthographic/phonetic surface structures because this is the main aim of building a universal model of perception and speech decoding. Equally important is the detection of morphological representations of lexical components, which include processing and encoding pure orthographic meanings (form level) or the idea of the semantic information (content components).

Traditional questions of the representation of morphological meaning overtones in the process of natural language decoding can be answered with a harmonious model that combines the basic notions of the priming theory and philological phenomenological hermeneutics. It should be noted that morphological structure is no way independent of the formal characteristics or semantics and noematics of the word in natural speech.

\section{Representation of morphological information in a complex model}

In general, a language has quite limited possibilities for fulfilling adequate control of the influence of conceptual similarity on the processes of speech perception within the route-priming effect. In this study, we attempt to come closer to this problem via introducing noematically and associatively similar prime/target pairs (i.e., doctornurse) based on the strategy of prognostic expectation as one of the meta-units of generating/encoding meaning in philological phenomenological hermeneutics. In regards to the route-priming effect within decoding the basic meaning, the semantic/associative prognostics always causes a less prominent effect. But it should be stressed that this input does not matter much within the phenomenological reflection (conscientious decoding of the inner meaning). This is due to the fact that conceptual similarity of the stimulus-pairs, which consist of the deviated form and a respective basic for, surely, cannot be compared to noematically linked and associative forms. Empirical verification of understanding can only be fulfilled via the kind of methodology that provides the variety of conceptual similarity, as well as the presentation of the constant morphological structure (to detect the stability of formants that realize morphological overtones). In this case, the principle of the 
uniqueness of morphological and semantical or morphological and noematic components comes into action, as it happens in, for say, compound words, and verbs with prefixes in the German language. In this case, priming does not always work because even some of the usual meanings cannot be subject to the component analysis. For example, the meaning of the compound word Blaustrumpf (German) cannot be interpreted via the semantic component analysis as it does not originate from the semantics of the word's components. Etymological re-division may have solved the problem, but then we would inevitably need to involve the main transformational opportunities of the meaning generation, the transformation of diffraction and modification into the sphere of understanding. "Diffraction/re-division of the existing knots of the structure and, vice versa, alternation of the opportunities to interpret the elements of the structure is based on the operations with epy core structures in route morphemes and affixes. Modification/specification of the relation between the represented quanta and a situation in the conditions of failed communication, correction as the result of phenomenological reflection" (Bredikhin 2013b: 490-491).

The meaning of the compound word Damenstrumpf is semantically transparent because etymological re-division, which does not involve intentional analysis of other types of meaning transformations, reveals all semantic, morphological and syntagmatic links. Potential usage of the compound and its equivalent in German, Strumpf für Damen, can be predicted on the basis of its components. Moreover, the meaning of verbs with particles or prefixes does not often correspond to the modified meaning of the basic form, which happens due to the involvement of additional overtones into the meaning structure (for example, German, besuchen, einschenken, vs. absuchen, beschebken). As a rule, derivation takes place with semantically transparent word-forms, the meaning of which stems from the meaning of the basic morpheme and different affixes (e.g., German unglücklich, geglückt, glücklich).

We should mention some differences in the degree of the representation and processing speed during reception and decoding of previous perceptions of the components and about the prognostics realization for semantically transparent compound words (e.g., English loop - loophole, hole - loophole) and non-transparent compounds (e.g., cook - cocktail, tail - cocktail). At the same time, there is the socalled constitutional priming effect in both cases. Nevertheless, the scale of these effects was much less prominent than when the whole compound word was represented within the prime or target (e.g., English cocktail-cocktail). The time of the reaction and the statistical error show no proof of interrelation between constitutional priming and semantic transparency.

However, based on the abovementioned thesis we cannot make the conclusion about each noema of the meaning hierarchy being recognized via the component and morphological analysis only because the study of almost identical effects reveals the so-called "pseudo-compounds" (e.g., English boycott or magpie). However, it should be noted that a special stimulus is an inevitable result of a recurrent primingparadigm, in which the prime and the target are usually spread across the time reception. Semantic and orthographic effects, as a rule, reveal within a very short period of time, and one should not expect their invariable presence in every situation that happens under the similar representation conditions. The differences which occur in similar situations within the long-term effects of recurring priming-paradigms are caused by the involvement of sporadic mechanisms of packaged storage of the "action schemes" during the reception of the uttering, i.e., due to the leveling of the very essence of the "action schemes" and turning them into frame-gestalt structures. This leads to an inability to make any conclusions of full value about the key points of lexical processes in the representation of the morphological information.

XLinguae, Volume 11 Issue 1, January 2018, ISSN 1337-8384, eISSN 2453-711X 
For the sake of illustration let us analyze the prime role of transparent and nontransparent compounds in the Dutch language with a simultaneous representation of the components of the compound targets. The degree of difficulty in interpretation and the time interval needed for decoding the meaning overtones demonstrate the closest interaction between the prime-type and its constituent. The reception of the transparent compound word, for example, Dutch kerkorgel (German Kirchenorgel) (a church body), is characterized by a high degree of the priming effect representation of the second component (orgel), which, so to say, is the semantic head of the compound word, i.e., it has a bigger semantic and derivational and compositional potential than the first component (Kerk). The priming effect for the first and the second component of non-transparent words, for example, Dutch drankorgel (drunkard), does not differ. The common constitutional priming effect depends, to some extent, on orthographic/phonetic closeness and cannot be determined based on any other data. It is important to stress the fact that constitutional priming reveals itself in regards to the semantic complexity of the compound word.

Within this study, we have also conducted a series of experiments on the lexical introduction of morphological information and the meaning overtones representation in German and Dutch phrasal verbs.

Phrasal verbs have morphologically complex word-forms in their paradigm, which due to the formal semantic complexity are subject to meaning modification. Thus, phrasal verbs are the verbs which still comprise a basic verb (as a core element), while their common generalized meaning can be easily predicted in the process of perception and decoding of the morphological and lexical (etymological) meaning of the prefix and the modified meaning of the basic verb (e.g., German aufwecken). Or they are the verbs the meaning of which cannot be predicted within an uttering based on the notion of the basic meaning of the verb only (e.g., German einwecken).

The results of the study based on the Dutch and German transparent and nontransparent phrasal verbs give the opportunity to create a general universal model of speech recognition. When the primes which include basic morphemes are represented in the capacity of the target under the unconcealed non-marginal conditions (e.g., Dutch neerschieten - schieten; voorschieten - schieten) a clearly shaped routepriming effect takes place. Compared to the experimental conditions in which semantically and orthographically/phonetically incompatible phrasal verbs precede the basic verb (e.g. Dutch doorbreken - schieten), it led to a number of outcomes for both transparent and non-transparent phrasal verbs, like the considerable reduction of the reaction time and the reduction of cognitive efforts which are required for decoding the generalized meaning. This happens because of the reduction of steps in the process of meaning desobjectivization. Nevertheless, there is a considerable difference in the extent to which the steps of phenomenological reflection are reduced under these conditions because in transparent phrasal verbs the prime-given (prerealization) produces a bigger effect than in the case of non-transparent phrasal verbs. However, even this data cannot provide a clear interpretation of the mechanisms that lie in the essence of representation processes of certain hierarchy overtones. The abovementioned results can be attributed to a route segmentation based on the surface morphological structures that are modeled via further semantic and noematic processing. They can also be explained from the viewpoint of the lexical processes activation, which is reflected in the reaction time delay to certain elements of representation (basic verb - transparent and non-transparent phrasal verbs).

The concealment of the prime can happen via marginal variants of perception, in particular of the early processing of the formal mechanisms of the word recognition. Therefore, the analysis and study of the same sets of components within concealed priming conditions should contribute to the general choice between the alternative approaches to desobjectivizain of the meaning construction. When making the final 
decision about the perception we employ more and more of new "action schemes," we search for each priming effect that would conform with the model under unconcealed conditions.

Moreover, orthographically/phonetically similar prime/target-combinations (e.g., German abmessen - essen - messen) are of particular interest as well. These do not lead to the reaction time reduction and do not have the time delay compared to the cases of experimental conditions. All these results refute psycholinguistic models according to which the procedure of concealment is characterized by the processes that influence the change of the reaction time, and those that are connected with the formal features analysis.

Taking into account the fact of revealing semantic or associative prime effects under the concealed priming conditions it is possible to make a conclusion about the influence of the semantical complexity in the cases of amphiboly of the meaning construction on the route priming in the concealment conditions. Furthermore, this fact allows for a deduction about the activation processes that are connected with the content features representation, rather than with orthographical and phonetic, and morphological surface structures.

As a result of the experiment data analysis within the orthographic and morphological priming it has been possible to find out that simple word-forms that have identical initial graphic/phonetic combinations and that are employed in the cases of nomination of the noesis situations, will have a further priming effect to them, which does not depend on the morphological status of the variable segments. The analysis of the route-priming effect of a phrasal verb reflects the involvement of the orthographic/phonetic introduction level while making deflation decisions at the level of lexical components. This is supported by the empirical data as well, and the effect of semantic transparency is admittedly the primary one, especially when realizing nomination tasks.

In the German language, an expressed priming effect is revealed in transparent phrasal and basic verbs. The decoding time for nominating processes in the cases of basic verbs, which was less than it was needed for non-transparent phrasal verbs, does not differ from the transparent verbs in the experimental conditions. In the experiments based on the Dutch language, it was possible to detect the priming effect with a varying degree, depending on the transparency of the phrasal verbs.

Thus, this tendency looks similar in both language systems in the situations of decoding the nominating components, and it cannot be explained by the fact of a special status of the route morpheme at the level of the morphological information input. It is also clear that the similarity in graphic/phonetic characteristics of the basic verb and the transparent or non-transparent phrasal verbs is not enough to cause correlating time reduction for generating/decoding nominative components within each situation. As there is no reaction time difference between similar (abmessen essen) and different prime/target-pairs, we believe that target nomination at the phase of lexical information pre-input can subsequently ease the task, if the prime is introduced earlier and via an approximately equal number of graphemes/phonemes. At this point, probably the most important role belongs to the concurrence of the initial position of letters/sounds in the word.

Perhaps the difference between the analysis of mechanisms of speech decoding based on the hermeneutical and noematic method and that of Miller and Neely's study is that in classic psycholinguistic experiments not enough attention is paid to the semantic transparency of the phrasal verbs. There is a number of verbs which have both transparent and non-transparent meaning components (e.g., German abtreiben meaning "einem manövrierunfähigen Boot" or with the component of the generalized meaning "Schwangerschaftsabbruch"). Hermeneutical and noematic analysis of the empirical material shows that only phrasal verbs with non-transparent generalized

XLinguae, Volume 11 Issue 1, January 2018, ISSN 1337-8384, eISSN 2453-711X 
meanings act as transparent verbs, which is also proved in the process of nomination in Dutch, where this factor explicitly varies.

On the whole, such experiments, regardless whether the methods employed take into consideration or ignore the main constants of the meaning generation which comprise morphologically complex words with similar morphological structures of different semantic complexity, demonstrate quite homogeneous study models. The latter does not touch upon the methods of representation, the type of target task and priming input, but they represent the most important conclusion about the route-priming effect: there is an obvious effect that happens due to the interrelation between the generalized meaning of the phrasal verb and the basic verb.

However, implementation of philological and phenomenological hermeneutics allows detecting quite clear connection to the primary lexical principle of organizing the effect in forming the decoding meaning based on the initial input. This leads to revealing semantic closeness between the representation of the basic morpheme and the complex connection to the lexical input of the corresponding word-form. At the same time there is no explicit proof of this phenomenon within the morphological decompositional theory, according to which the route-priming effect is detected mostly in morphologically-encoded phonetic/orthographical units of input. Moreover, the effect is modeled via the following semantic processing.

This proposition returns us to the important problem of discussing the most effective approaches, which are balanced contamination for the analysis at the level of morphological structures input as well as for the phonetically/orthographically similar elements. Obviously, despite the theories suggested in the psycholinguistic literature, purely experimental paradigms are not enough for detecting effects at different levels of the hypothetical mental lexicon.

One of the ways to study morphological structures together with the lexical components of the meaning, regardless of the phonetic/orthographic design of the word-form, is through the associative priming-paradigm. Associative priming effect reveals itself in the course of measures in the experimental conditions where there are the reaction time reduction and the reduction of the time for decoding the target word. This has a high associative capacity for the prime (as in the pair Tisch - Stuhl). As a rule, this method is used (Neely 2001). As for the question about lexical realization of morphological and semantical principles of the organization, they also can be analyzed within this paradigm, where the question is also researched about the connection of generalized meaning of morphologically complex word-forms and representations of the components of meaning of their constituent parts, in particular, even if the generalized meaning cannot be derived from the combination of the meanings of the separate components, and has nothing common with them.

Within the hermeneutical noematic analysis we have conducted an experiment which combines transparent and non-transparent compound words with associatively close target words in the Dutch language material that create an association either according to the first or the second element (kerkorgel - priester, kerkorgel - muziek; drankorgel - bier, drankorgel - muziek). Compared to the experimental conditions, we found out that in general there is a significant reduction of latency (an application of noematic reflection that appears in a shorter reception time interval - in the decoding of target) during the process of perception and increase of the involvement of phenomenal (conscious) reflection level for the target words that had transparent and non-transparent compounds with associatively close priming effects. Moreover, the significant relation has been revealed between associative priming and semantical complexity of the compound word. Transparent compounds (kerkorgel) cause a clearly stronger priming effect together with the association for the second element (muziek) than for the first one (priester). But for the non-transparent compounds, there is no difference in the priming effect of the associative row for the first or for the 
second of the components. It is quite an interesting fact that this data is also the exemplary demonstration of the results that have been indicated earlier during the process of the analysis of the constitutional priming effect, where there is the priming effect for the recurrent representation of the compounds (kerkorgel-kerk, drankorgel - orgel, etc.), and to the same extent there is the dependence on the semantical complexity of the compounds.

Both of the conducted experiments prove that the component priming returns to another phonetic/orthographic representation of the components which is impossible for the associative priming. Besides, it is clear that the observed effects are involved not only in the processes that reflect similarity activation between the generalized meaning of the compound and its associations. "Bier" as the meaning of the nontransparent compound "drankorgel" (drunkard) is closer defined semantically than "muziek"; both associations show an equal priming effect. These facts show the meaning of the components will be processed without an attraction of the morphological structure. This statement is confirmed be the analysis of the complex substantives, such as "aalmoes" (Aalmosen), the generalized meaning of which doesn't have any connection with the components "aal" (Aal) and "moes" (Kompott). This compound word causes an effect of facilitation of the decoding only for the target word, and this effect corresponds with an association of the complete wordform (aalmoes-bedelaar; Aalmosen-Bettler). For the target word which forms an association with the first component, on the contrary, there appears considerable inhibitory effect (almoes - vis; Almosen - Fisch), which means that in comparison with the experimental conditions of decoding, the recognition of the target word will require more much time and efforts to construct a phenomenological reflection. The time delay for the second component of the associated target words does not have any serious difference from the experimental conditions.

\section{Conclusion}

Thus the studies that focus on processing the morphologically complex words, which differ in terms of the semantic complexity, suggest that the input of the prime target into the hypothetical mental lexicon involves a parallel impact of the morphologically complex word forms and Individual components of the complete morphemes. Along with this a direct connection (in transparent forms) can be traced, as well as an indirect connection (in non-transparent forms) of the verbal representations - the fact that defines the general semantic features and possible morphological compatibility of the components. In addition, we can make a decision about the closest and consistent interrelation of structural and noematic components of simple and complex structures in different Germanic languages. A noematic structure (total generalized sense) of language units represent not a countable simplest set of noematic components, but a syncretic inseparable unity - be the information input complex or non-complex where each component has no fixed place yet presents a dynamic value within a flexible and constantly transforming structure.

\section{Bibliographic references}

BERGMAN, M.W. - HUDSON P.T.W. - ELING P.A.T.M. 1988. How simple complex words can be: Morphological processing and word representation. In: The Quarterly Journal of Experimental Psychology, vol. 40A, n. 1, pp. 41-72. ISSN 10888438 .

BREDIKHIN, S.N. 2013a. Etymological metanalysis and synthesis as basic mechanisms of diffraction and modification of sense superstructure. In: Fundamental researches, n. 6-2, pp. 490-494. ISSN 1812-7339.

XLinguae, Volume 11 Issue 1, January 2018, ISSN 1337-8384, eISSN 2453-711X 
BREDIKHIN, S.N. 2013b. Principles and conditions of sense existence and derivation (sense derivation mechanisms). In: Modern problems of science and education, n. 1, pp. 374-381. ISSN 2070-7428.

CARR, T.H. - POLLATSEK, A. 1985. Recognizing printed words: A look at current models. In: Reading research: Advances in theory and practice, vol. 5. New York: Academic Press. ISBN 0-12-572303-2.

FARKE, H. - FELIX, S.W. 1990. Struktur und Funktion des Lexikons in der menschlichen Sprachverarbeitung. In: Sprache und Wissen. Studien zur Kognitiven Linguistik, Opladen: Westdeutscher Verlag GmbH. ISBN 978-3-663-05395-8.

FELDMAN, L.B. 1991. The contribution of morphology to word recognition. In: Psychological Research, n. 53, pp. 33-41. ISSN 0340-0727.

FORSTER, K.I. 1981. Priming and the effects of sentence and lexical context on naming time: Evidence for autonomous lexical processing. In: Quatterly Journal of Experimental Psychology, n. 33A, pp. 465-495. ISSN 0272-4987.

FRAUENFELDER, U.H. - SCHREUDER, R. 1992. Constraining psycholinguistic models of morphological processing and representation: The role of productivity. In: Yearbook of Morphology. Dordrecht: Kluwer Academic Publishers. ISBN 0-79233984-3.

GALUSHKIN, A. 2015. Internet in modern Russia: History of development, place and role. In: Asian Social Science, vol. 11, n. 18. pp. 305-310. ISSN 1911-2017 (Print) ISSN 1911-2025 (Online)

GRAINGER, J. - COLE, P. - SEGUI, J. 1991. Masked morphological priming in visual word recognition. In: Journal of Memory and Language, n. 30, pp. 370-384. ISSN 0749-596X.

GRUDTSINA, L.J. - GALUSHKIN, A.A. 2013. Questions of modern civil society development in Russian Federation. In: World Applied Sciences Journal, vol. 25, n. 5, pp. 790-793. ISSN 1818-4952.

GÜNTHER, H. 1989. Experimentelle Morphologieforschung. In: Experimentelle Studien zur deutschen Flexionsmorphologie. Hamburg: Helmut Buske Verlag, pp. 926. ISBN 3-87118-969-3.

HANKAMER, J. 1991. Morphological parsing and the lexicon. In: Lexical representation and process / Ed. by W.D. Marslen-Wilson. Cambridge, MA.: MIT Press, pp. 392-408. ISBN 9780262279178.

HENDERSON, L. 1991. On mental representation of morphology and its diagnosis by measures of visual access speed. In: Lexical representation and process. Cambridge, MA: MIT Press, pp. 357-391. ISBN 9780262279178.

KONG, Y. - KAYUMOVA, L.R. - ZAKIROVA, V.G. (2017). Simulation Technologies in Preparing Teachers to Deal with Risks. In: EURASIA Journal of Mathematics, Science and Technology Education, vol. 13, n. 8, pp. 4753-4763. ISSN $13058215,13058223$.

MILLER, G.A. - JOHNSON-LAIRD, P.N. 1976. Language and Perception. Cambridge: Cambridge University Press. ISBN 9780674421288.

MURRELL, G.A. - MORTON, J. 1984. Word recognition and morphemic structure. In: Journal of Experimental Psychology, n. 102, pp. 963-968. ISSN 0090-502X.

NEELY, J. H. 2001. Semantic priming effects in visual word recognition: A selective review of current findings and theories. In: Basic processes in reading: Visual word recognition / Ed. by D. Besner, G. Humphreys. Hillsdale, NJ: Erlbaum, pp. 264-336. ISSN 1069-9384.

SCHRIEFERS, H. - FRIEDERICI, A. - GRAETZ, P. 1997. Inflectional and derivational morphology in the mental lexicon: Symmetries and asymmetries in repetition priming. In: The Quarterly Journal of Experimental Psychology, vol. 44A, n. 2, pp. 373-390. ISSN 0090-502X. 
SEIDENBERG, M.S. - MCCLELLAND, J.L. 1989. Sublexical structures in visual word recognition: Access units or orthographic redundancy? In: A distributed, developmental model of word recognition and naming. Psychological Review, n. 96, pp. 523-568. ISSN 0033-295X.

SPENCER, A. 1991. Morphological theory: An Introduction to Word Structure in Generative Grammar. Oxford: Blackwell Publishers. ISBN 978-0-631-16144-8.

STANNERS, R.F. - NEISER, J.J. - HEROON, W.P. - HALL R. 1979. Memory representation for morphologically related words. In: Journal of Verbal Learning und Verbal Behavior, n. 4, pp. 399-412. ISSN 0022-5371.

TAFT, M. - FORSTER, K.L. 1975. Lexical storage and retrieval of polymorphemic and polysyllabic words. In: Journal of Verbal Leaming und Verbal Behavior, vol. 14, n. 6, pp. 607-620. ISSN 0022-5371.

TAFT, M. 1991. Reading and the mental lexicon. Hove: Lawrence Erlbaum Associates Ltd. ISBN 1135064539.

Words: 6585

Characters: 45614 (25,34 standard pages)

Prof. Rashid Alikaev, Dr. Philol.

Department of German and Roman philology

Kabardino-Balkarian State University named after H. M. Berbekov

173 Chernyshevsky Str.

360004, Nalchik

Russia

ralikaev@mail.ru

Senior lecturer Marianna Asanova, $\mathrm{PhD}$

Kabardino-Balkarian State University named after H. M. Berbekov

Department of Foreighn languages

173 Chernyshevsky Str. 360004, Nalchik

Russia

asanovamarianna2017@mail.ru

Prof. Tatiana Shiryaeva, Dr. Philol.

Department of English language and professional communication

Pyatigorsk State University

63 Kirov Str. 357502, Pyatigorsk

Russia

shiryaevat@list.ru

Assoc. Prof. Tatiana Cheprakova, PhD

Kabardino-Balkarian State University named after H. M. Berbekov

Department of General linguistics and Russian language

173 Chernyshevsky Str. 360004. Nalchik

Russia

dissovet2012@mail.ru

Prof. Sergey Bredikhin, Dr. Philol.

North Caucasus Federal University

Department of Translation and interpretation

1 Pushkin Str. 355009, Stavropol

Russia

bredichinsergey@yandex.ru

XLinguae, Volume 11 Issue 1, January 2018, ISSN 1337-8384, eISSN 2453-711X 